\title{
Detection of metabolic syndrome features among childhood cancer survivors: A target to prevent disease
}

\author{
Adriana Aparecida Siviero- \\ Miachon' \\ Angela Maria Spinola- \\ Castro' \\ Gil Guerra-Junior ${ }^{2}$ \\ 'Division of Pediatric Endocrinology, \\ Department of Pediatrics, Federal \\ University of Sao Paulo - UNIFESP/ \\ EPM, Brazil; ${ }^{2}$ Division of Pediatric \\ Endocrinology, Department of \\ Pediatrics, State University of \\ Campinas - FCM/UNICAMP, Brazil
}

\begin{abstract}
Along with the growing epidemic of obesity, the risk of atherosclerosis, cardiovascular disease morbidity, and mortality are increasing markedly. Several risk factors for cardiovascular disease, such as visceral obesity, glucose intolerance, arterial hypertension, and dyslipidemia commonly cluster together as a condition currently known as metabolic syndrome. Thus far, insulin resistance, and endothelial dysfunction are the primary events of the metabolic syndrome. Several groups have recommended clinical criteria for the diagnosis of metabolic syndrome in adults. Nonetheless, in what concerns children and adolescents, there are no unified definitions, and modified adult criteria have been suggested by many authors, despite major problems. Some pediatric disease states are at risk for premature cardiovascular disease, with clinical coronary events occurring very early in adult life. Survivors of specific pediatric cancer groups, particularly acute lymphocytic leukemia, central nervous system tumors, sarcomas, lymphomas, testicular cancer, and following bone marrow transplantation, may develop metabolic syndrome traits due to: hormonal deficiencies (growth hormone deficiency, thyroid dysfunction, and gonadal failure), drug or radiotherapy damage, endothelial impairment, physical inactivity, adipose tissue dysfunction, and/or drug-induced magnesium deficiency. In conclusion, some primary and secondary prevention remarks are proposed in order to reduce premature cardiovascular disease risk in this particular group of patients.
\end{abstract}

Keywords: metabolic syndrome X, cardiovascular diseases, insulin resistance, obesity, growth hormone/deficiency, endothelium, vascular/physiopathology

\section{Metabolic syndrome and cardiovascular disease}

Along with the growing epidemic of obesity and chronic diseases, the risk of atherosclerosis, as well as cardiovascular disease (CVD) morbidity and mortality, are increasing markedly (Waychenberg 2000). Reaven (1988) noted that several risk factors for CVD commonly cluster together, and he recognized them as a disease, named syndrome X, currently known as metabolic syndrome (MS). Insulin resistance (IR) is considered the primary cause of associated cardiovascular risk factors and the probable mechanism linking all the MS comprising features, such as visceral obesity, glucose intolerance, type 2 diabetes mellitus (T2DM), arterial hypertension, atherogenic dyslipidemia, proinflammatory, and prothrombotic state (Sarti and Gallagher 2006).

Viscerally distributed adipose tissue, rather than subcutaneous fat, plays a major role in this process (Waychenberg 2000). Adipose tissue is controlled by several signals, including insulin and growth hormone (GH), and has been considered as an endocrine organ (Mohamed-Ali et al 1998). Adipocytes secrete inflammatory mediators and adipokines (comprising leptin and adiponectin), that regulate endothelial function, atherogenesis, and energetic balance. Adipokines also activate intracellular pathways, regulating the subacute inflammatory state associated with obesity, and 
the development of IR and T2DM (Shoelson et al 2006). Endothelial dysfunction (reflected principally by microalbuminuria) is associated with MS components, and is present in patients suffering from atherosclerosis. Overall, it is not clear yet whether IR is cause or consequence of endothelial dysfunction (Nuver et al 2002). To date, an increased risk of CVD death is more pronounced when MS itself is present. However, each individual component of MS may also confer increased occurrence of CVD. So far, the more components of MS that are evident, higher is the cardiovascular mortality rate (Hu et al 2004).

\section{Defining metabolic syndrome}

Several groups have recommended clinical criteria for the diagnosis of MS in adults (Alberti and Zimmet 1998; Balkau and Charles 1999; ADA 2000; NCEP-ATP III 2001; Einhorn et al 2003; Genuth et al 2003; Grundy et al 2004; IDF 2006). Definition data regarding different criteria are summarized in Table 1.

In what concerns the pediatric population, there are several difficulties in determining MS features. Some authors have proposed modified adult criteria, taking into account child specific cutoff values and percentiles (Cook et al 2003; Cruz et al 2004; DeFerranti et al 2004; Weiss et al 2004;
Jones 2006). Insulin sensitivity, an important diagnostic condition for MS, is difficult to obtain, especially in pediatric patients. To date, hyperinsulinemic clamp has been considered the gold-standard for insulin evaluation, but this is a complicated method to be applied in children. Moreover, insulin sensitivity changes with age and puberty, while it is negatively correlated with visceral obesity. Data for percentiles of waist circumference that are specific to ethnic origin are becoming increasingly available (Zimmet et al 2007), and have been suggested in MS definition criteria in pediatric patients, rather than body mass index (BMI). In addition, BMI was converted to standard deviation scores (SDS) or percentiles for comparisons, with the basis of the National Center for Health Statistics (NCHS) 2000 international reference. Blood pressure percentiles were determined according to the National High Blood Pressure Education Program Working Group on Hypertension Control in Children and Adolescents (1996), while lipid levels were analyzed with the basis of different existing criteria (AAP 1992; Hickman et al 1998). On the other hand, the International Diabetes Federation (IDF) has recently redefined MS in children and adolescents, and has proposed requiring parameters in absolute values, rather than age-related percentile cutoffs. Moreover, it has also been suggested that MS should not be diagnosed in children

Table I Metabolic syndrome definition in adults according to different criteria (Adapted from Grundy et al 2004)

\begin{tabular}{|c|c|c|c|c|c|}
\hline Risk factors & WHO (1998) & EGIR (1999) & NCEP-ATP III (200I) & AACE (2003) & IDF (2006) \\
\hline Requirement & $\begin{array}{l}\text { T2DM, impaired fast- } \\
\text { ing glucose, IGT or IR } \\
\text { (HOMA-IR) }+\geq 2 \text { of } \\
\text { the following }\end{array}$ & $\begin{array}{l}\text { Hiyperinsulinemia } \\
\text { or } I R+\geq 2 \text { of the } \\
\text { following }\end{array}$ & $\geq 3$ of the following & $\begin{array}{l}\text { Depends on clinical } \\
\text { judgment based } \\
\text { on risk factors as } \\
\text { following* }\end{array}$ & $\begin{array}{l}\text { Central obesity }+ \\
\geq 2 \text { of the following }\end{array}$ \\
\hline Blood pressure & $\begin{array}{l}\text { Antihypertensive drug } \\
\text { and/or } \geq 140 / 90 \mathrm{mmHg} \\
\text { with no treatment }\end{array}$ & $\begin{array}{l}\geq 140 / 90 \mathrm{mmHg} \text { or } \\
\text { antihypertensive drug }\end{array}$ & $\geq 130 / 85 \mathrm{mmHg}$ & $\geq 130 / 85 \mathrm{mmHg}$ & $\begin{array}{l}\text { Antihypertensive } \\
\text { drug or } \geq 130 / 85 \\
\mathrm{mmHg}\end{array}$ \\
\hline Triglycerides & $\geq 150 \mathrm{mg} / \mathrm{dL}$ & $\geq 180 \mathrm{mg} / \mathrm{dL}$ & $\geq 150 \mathrm{mg} / \mathrm{dL}$ & $\geq 150 \mathrm{mg} / \mathrm{dL}$ & $\geq 150 \mathrm{mg} / \mathrm{dL}$ \\
\hline HDL-cholesterol & $\begin{array}{l}\mathrm{M}:<35 \mathrm{mg} / \mathrm{dL} \mathrm{F}: \\
<39 \mathrm{mg} / \mathrm{dL}\end{array}$ & $<40 \mathrm{mg} / \mathrm{dL}$ & $\begin{array}{l}\mathrm{M}:<40 \mathrm{mg} / \mathrm{dL} \mathrm{F}:<50 \\
\mathrm{mg} / \mathrm{dL}\end{array}$ & $\begin{array}{l}\mathrm{M}:<40 \mathrm{mg} / \mathrm{dL} \mathrm{F}: \\
<50 \mathrm{mg} / \mathrm{dL}\end{array}$ & $\begin{array}{l}\mathrm{M}:<40 \mathrm{mg} / \mathrm{dL} \\
\mathrm{F}:<50 \mathrm{mg} / \mathrm{dL}\end{array}$ \\
\hline Central obesity & $\begin{array}{l}\mathrm{BMI}>30 \mathrm{~kg} / \mathrm{m}^{2} \text { and } / \mathrm{or} \\
\mathrm{M}: \mathrm{W} / \mathrm{H}>0.90 \mathrm{~F}: \mathrm{W} / \mathrm{H} \\
>0.85\end{array}$ & $\begin{array}{l}M: W \geq 94 \mathrm{~cm} \mathrm{~F}: W \\
\geq 80 \mathrm{~cm}\end{array}$ & $\begin{array}{l}M: W>102 \mathrm{~cm} \mathrm{~F}: W \\
>88 \mathrm{~cm}\end{array}$ & $\begin{array}{l}\mathrm{BMI} \geq 25 \mathrm{~kg} / \mathrm{m}^{2} \mathrm{M}: \\
\mathrm{W}>102 \mathrm{~cm} \mathrm{~F}: \mathrm{W} \\
>88 \mathrm{~cm}\end{array}$ & $\begin{array}{l}M: W \geq 94 \mathrm{~cm} \\
F: W \geq 80 \mathrm{~cm}\end{array}$ \\
\hline Microalbuminuria & $\geq 20 \mu \mathrm{g} / \mathrm{min}$ & - & - & - & - \\
\hline Glucose/insulin & $\begin{array}{l}\text { T2DM, impaired fasting } \\
\text { glucose, IGT or IR } \\
\text { (HOMA-IR) }\end{array}$ & $\begin{array}{l}\text { Fasting glucose } \geq 110 \\
\mathrm{mg} / \mathrm{dL}^{\ddagger}\end{array}$ & $\begin{array}{l}\text { Fasting glucose } \geq 110 \\
\mathrm{mg} / \mathrm{dL} \neq\end{array}$ & $\begin{array}{l}\text { Fasting glucose } \\
\text { I I } 0-125 \mathrm{mg} / \mathrm{dL}^{\ddagger} \text { or } \\
\text { IGT }\end{array}$ & $\begin{array}{l}\text { Fasting glucose } \\
\geq 100 \mathrm{mg} / \mathrm{dL} \\
\text { (OGTT recom- } \\
\text { mended) or previ- } \\
\text { ous T2DM }\end{array}$ \\
\hline
\end{tabular}

Abbreviations:WHO,World Health Organisation (Alberti and Zimmet 1998); EGIR, European Group for the Study of Insulin Resistance (Balkau and Charles I999); NCEP-ATPIII, National Cholesterol Education Program-Adult Treatment Panel III (NCEP-ATP III 200 I);AACE, American College of Endocrinology/American Association of Clinical Endocrinologist (Einhorn et al 2003); IDF, International Diabetes Federation (2006);T2DM, type 2 diabetes mellitus (fasting glucose $>$ I $26 \mathrm{mg} / \mathrm{dL}$ ); IGT, Impaired glucose tolerance'; IR, insulin resistance; HOMA-IR, homeostasis model assessment; M, male; F, female; BMI, body mass index; W, waist; H, hip;W/H, waist to hip ratio; OGTT, oral glucose tolerance test. Notes: *Other risk factors: polycystic ovary syndrome, sedentary lifestyle, advancing age, ethnic groups having high risk for T2DM or cardiovascular disease; ${ }^{\dagger} \mathrm{IGT}$ : OGTT post-2 $\mathrm{h}$ glucose $>140 \mathrm{mg} / \mathrm{dL}$ and $<200 \mathrm{mg} / \mathrm{dL}$; ${ }^{\ddagger}$ American Diabetes Association (ADA 2000). However, a cutpoint of $\geq 100 \mathrm{mg} / \mathrm{dL}$ has been recently established, and should be applicable for identifying the lower boundary to define an elevated glucose as one criterion for the metabolic syndrome (Genuth et al 2003). 
younger than 10 years, even though visceral obesity should call for attention (Zimmet et al 2007). See Table 2.

\section{Pediatric patients at high-risk: Attention to childhood cancer survivors}

The prevalence of MS and risk assessment is quite diverse, depending on the diagnostic criteria and assortment of population, but there is full agreement that it is clearly growing in overweight adults and pediatric patients (Grundy et al 2004). Notwithstanding, several pediatric conditions predisposing to the syndrome, as well MS comprising traits, should be identified earlier in childhood, in order to prevent CVD in adult life (Zimmet et al 2007). Typical examples are homozygous hypercholesterolemia, diabetes mellitus, chronic kidney disease, congenital heart disease, heart transplantation, Kawasaki disease, chronic inflammatory disease, systemic lupus erythematosus, rheumatoid arthritis, and cancer treatment during childhood (Kavey et al 2006).

In the last twenty years, along with the better care committed to children with cancer, the establishment of chemotherapy (CT) and the advances in radiotherapy (RT), survival rates have greatly improved. Consequently, the number of patients that reach adulthood presenting some treatment-related health problems or mortality due to CVD is increasing continuously
(Oeffinger et al 2001). According to a statement developed by the American Heart Association along with the Council for Cardiovascular Disease in the Young, based on the study of several pediatric states and their risk for CVD, post-cancer treatment survivors were classified as tier III, which means increased cardiovascular risk factors, with epidemiological evidence for manifest CVD early in adult life, but after 30 years of age (Kavey et al 2006). Survivors of specific pediatric cancer groups, particularly acute lymphocytic leukemia (ALL), central nervous system (CNS) tumors, sarcomas, lymphomas, disseminated testicular cancer, neuroblastomas, Wilms tumors, and following bone marrow transplantation (BMT), are recognized to present clinical features of MS, and therefore increased risk factors for CVD, such as visceral obesity, IR, glucose intolerance, dyslipidemia, arterial hypertension, and endothelial dysfunction (Heikens et al 2000; Oeffinger et al 2001; Link et al 2004; Nuver et al 2005; Gurney et al 2006; Neville et al 2006; Janiszewski et al 2007; Razzouk et al 2007; Taskinen et al 2007; Trimis et al 2007; Hoffman et al 2008).

\section{Metabolic syndrome and cancer: What comes first?}

Different studies have shown that cancer and several chronic diseases may have some risk factors in common, considered features of MS, such as obesity, hyperinsulinemia, and IR.

Table 2 Metabolic syndrome definition in children and adolescents according to different criteria (Adapted from Jones 2006; Zimmet et al 2007)

\begin{tabular}{|c|c|c|c|c|c|}
\hline Risk factor & Cook et al 2003 & Cruz et al 2004 & $\begin{array}{l}\text { DeFerranti } \\
\text { et al } 2004\end{array}$ & Weiss et al 2004 & IDF 2007 \\
\hline Requirement & $\begin{array}{l}3 \text { out of } 5 \text { of the } \\
\text { following }\end{array}$ & $\begin{array}{l}3 \text { out of } 5 \text { of the } \\
\text { following }\end{array}$ & $\begin{array}{l}3 \text { out of } 5 \text { of the } \\
\text { following }\end{array}$ & $\begin{array}{l}3 \text { out of } 5 \text { of the } \\
\text { following }\end{array}$ & $\begin{array}{l}\text { BMI } \geq 90 \text { th percentile }+\geq 2 \\
\text { of the following }\end{array}$ \\
\hline Age (years) & $12-19$ & $8-13$ & $12-19$ & $4-20$ & $10-16$ \\
\hline Blood pressure & $\begin{array}{l}\geq 90 \text { th percentile } \\
\text { or antihypertensive } \\
\text { drug }\end{array}$ & $>90$ th percentile & $>90$ th percentile & $>95$ th percentile & $\begin{array}{l}\text { Systolic blood pressure } \\
\geq 130 \mathrm{mmHg} \text { or diastolic } \\
\geq 85 \mathrm{mmHg}\end{array}$ \\
\hline Triglycerides & $\geq 110 \mathrm{mg} / \mathrm{dL}$ & $\geq 90$ th percentile & $\geq 100 \mathrm{mg} / \mathrm{dL}$ & $\geq 95$ th percentile & $\geq 150 \mathrm{mg} / \mathrm{dL}$ \\
\hline HDL-cholesterol & $\leq 40 \mathrm{mg} / \mathrm{dL}$ & $\leq 10$ th percentile & $\begin{array}{l}\mathrm{M}^{*}:<45 \mathrm{mg} / \mathrm{dL} \\
\mathrm{F}:<50 \mathrm{mg} / \mathrm{dL}\end{array}$ & $<5$ th percentile & $<40 \mathrm{mg} / \mathrm{dL}$ \\
\hline Central obesity & $\begin{array}{l}\text { BMI } \geq 95 \text { th } \\
\text { percentile } W \geq 90^{\text {th }} \\
\text { percentile }\end{array}$ & $W \geq 90$ th percentile & $\begin{array}{l}W>75 \text { th per- } \\
\text { centile }\end{array}$ & $\mathrm{BMI} \geq 2 \mathrm{SDS}$ & $W>90$ th percentile \\
\hline Glucose/insulin & $\begin{array}{l}\text { Fasting glucose } \\
\geq 110 \mathrm{mg} / \mathrm{dL}^{\ddagger} \\
\text { IGT,T2DM or IR } \\
\text { (HOMA-IR) }\end{array}$ & IGT & $\begin{array}{l}\text { Fasting glucose } \\
\geq 110 \mathrm{mg} / \mathrm{dL}^{\ddagger}\end{array}$ & $\begin{array}{l}\text { IGT or IR } \\
\text { (HOMA-IR) }\end{array}$ & $\begin{array}{l}\text { Fasting glucose } \geq 100 \mathrm{mg} / \mathrm{dL} \\
\text { (OGTT recommended) or } \\
\text { T2DM }\end{array}$ \\
\hline
\end{tabular}

Abbreviations: IDF, International Diabetes Federation (Zimmet et al 2007); BMI, body mass index;W, waist; IGT, impaired glucose tolerance ${ }^{\dagger}$ T2DM, type 2 diabetes mellitus; IR, insulin resistance; HOMA-IR, homeostasis model assessment; M, male; F, female; SDS, standard deviation score; OGTT, oral glucose tolerance test.

Notes: ${ }^{\dagger}$ GGT: OGTT post-2 h glucose $>140 \mathrm{mg} / \mathrm{dL}$ and $<200 \mathrm{mg} / \mathrm{dL} ;{ }^{*}$ Males $15-19 \mathrm{yr} ;{ }^{\ddagger}$ American Diabetes Association (ADA 2000). However, a cutpoint of $\geq 100 \mathrm{mg} / \mathrm{dL}$ has been recently established, and should be applicable for identifying the lower boundary to define an elevated glucose as one criterion for the metabolic syndrome (Genuth et al 2003). 
Nonetheless, it remains controversial if such risk factors are cause or consequence of chronic diseases, including cancer (Hsu et al 2007).

The association between diabetes mellitus and cancer was reported more than 100 years ago (Harish et al 2007), and population studies have shown increased evidence that MS is increasing worldwide, in parallel with an increasing of cancer incidence (Zhou et al 2007). Moreover, diabetes and obesity have been recognized as risk factors for the development of breast, endometrial, colorectal, and pancreatic carcinomas. To date, the association between diabetes, obesity, and cancer incite speculations about the mechanisms linking IR and adiposity, components of MS, and the development of certain types of cancer. However, the relation between MS (and its consequent biochemical derangements) and cancer still remains unexplained (Harish et al 2007).

Carcinogenesis is multifactorial, and depends not only on metabolic disturbances, but also on the inherited genetic background. Part of the carcinogenic effect could be attributed to adiposity, through hyperinsulinism, and additional mechanisms, that may include chronic inflammation and oxidative stress associated with obesity (Harish et al 2007; Hsu et al 2007). Insulin itself may also be an important factor linking IR to cancer (Hsu et al 2007). Previous statements have shown ample evidence suggesting that high levels of insulin (due to IR) increase insulin-like growth factor (IGF)-1 bioavailability by means of suppression of IGF binding protein 1 and 3 (IGFBP-1 and 3). IGF-1 has a role in promoting carcinogenesis and IGF-1 receptor is crucial for tumor transformation, and survival of malignant cells. Moreover, specific polymorphisms in certain genes encoding proteins involved in IGF-signaling pathway, including IGF-1 itself, are associated with variation in cancer risk (Harish et al 2007; Pollak 2007; Zhou et al 2007).

On the other hand, it remains highly controversial if carcinogenesis could possibly contribute to the development of MS in survivors of various malignancies. This is still little understood, but there are several speculations over it. The neoplasms may probably cause changes on insulin sensitivity, lipid metabolism, inflammatory mediators, and adipokines, which may be aggravated by anticancer therapies, including CT and RT. Thus far, the best biological model to study the relationship between cancer and the components of MS is cancer cachexia, which affects more than a half of cancer patients (Saini et al 2006). Cancer cachexia is considered a complex and multifactorial metabolic disorder involving features of anorexia, asthenia, lipolysis, changes in body composition, systemic inflammation, IR, and may predispose to long-term metabolic disturbances, and decreased lean body mass and muscles, that remain insulin resistant, analogous to the state proposed by the Barker hypothesis after intrauterine growth retardation (Barker 1995; Saini et al 2006).

\section{Metabolic syndrome features in childhood cancer survivors}

Thus far, the mechanisms behind increased cardiovascular risk factors in childhood cancer survivors are not clarified yet. Notwithstanding, there is a strong possibility that some pathways, different from those in non-cancer populations, may be activated in childhood cancer survivors, underlying mechanisms for weight gain and IR. These include various hormones deficiencies, changes on insulin sensitivity, lipid metabolism, inflammatory mediators and adipokines, as well as reduced physical activity, which may be altered by various cancer therapies. Local treatments, such as surgery and RT, may lead to multiple endocrine deficiencies and, consequently, to MS comprising features. Systemic treatments, like CT, may contribute to MS in several ways: damage of endocrine organs or nonhormonal systems, such as magnesium metabolism, as well as endothelial, and adipose tissue dysfunction (Nuver et al 2002; Kavey et al 2006).

Regarding childhood cancer survivors at risk for MS, and consequently considered at risk for premature development of CVD, we described the possible mechanisms determining MS, focusing on specific pediatric cancer groups, in which weight gain, endocrine and metabolic disturbances are especially prevalent.

\section{Mechanisms of metabolic syndrome in childhood cancer survivors Growth hormone deficiency and intima-media thickness}

Growth hormone (GH) deficiency in childhood cancer survivors may be attributed to the tumor itself, depending on the location in the hypothalamic-pituitary region, or to an adverse effect of treatment, comprising cranial RT, and/or CT. GH is implicated not only in growth regulation, but also in metabolism. GH deficiency frequently induces MS-like disorders, such as hypertriglyceridemia, low HDL-cholesterol, coagulopathy, and hypertension. Despite evidence linking GH deficiency to the components of MS and CVD, the relationship between the syndrome and GH secretion status has not been established yet. Thus far, two important conditions related to GH deficiency, IR and endothelial dysfunction, justify especial considerations (Nuver et al 2002). 
So far, increased intima-media thickness (IMT), an intermediate marker for CVD, has been described in the common carotid arteries of untreated children and adults with $\mathrm{GH}$ deficiency, and has been inversely correlated with IGF-1 levels (Szczepaniska-Kostro et al 2004; Soares et al 2005). In what concerns oncologic patients, no differences were recorded in artery thickness between ALL survivors regardless of cranial RT at dose up to 24 Gy (Oeffinger et al 2001; Link et al 2004). In contrast, an increased IMT in the carotid bulb of childhood CNS tumors survivors who received high-dose cranial RT ( $>45$ Gy) was described by Heikens and colleagues (2000). In conclusion, IMT seems to be positively correlated with cranial RT dose employed, and negatively correlated with IGF-1 levels, which in turn reflect GH status.

To date, GH replacement therapy in both oncologic and nononcologic GH-deficient patients can improve morphological and functional changes predisposing to CVD, particularly body composition (Bülow et al 2004; Colao et al 2005; Soares et al 2005). Nevertheless, the positive effects of GH replacement while on therapy usually do not persist after $\mathrm{GH}$ is discontinued, and depend on the period of replacement. A short-term GH replacement (12 months) induces favorable outcome, comprising metabolic parameters and body composition, however the beneficial effects on vascular damage (IMT) are only seen after long-term GH therapy (2 years) (Soares et al 2005). Finally, IMT was not prospectively evaluated while on GH therapy in the oncologic population (Bülow et al 2004).

\section{Thyroid dysfunction}

Thyroid dysfunction is an important adverse late-effect of cancer therapy, especially after neck RT, as CT alone does not possibly impair thyroid function. Several malignancies, encompassing tumors of CNS requiring craniospinal RT (medulloblastomas), lymphomas or neck tumors requiring locally administered RT, as well as following conditioning total body irradiation (TBI) before BMT, are at risk for thyroid dysfunction (Nuver et al 2002; Gleeson and Shalet 2004).

The hypothyroid state affects the cardiovascular system through both an influence on the heart and adverse effects on serum lipids, increasing the risk of development of CVD (Nuver et al 2002). Nevertheless, subclinical hypothyroidism, a state with elevated thyroid stimulating hormone (TSH) concentrations ( $>5.0 \mathrm{mIU} / \mathrm{L})$ and normal levels of thyroxin (T4) and triiodothyronine (T3) in asymptomatic subjects, commonly presented in long-term survivors of cancer, was not associated with increased risk for CVD (Nuver et al 2002). According to the European Organisation for Research and Treatment of Cancer database, in-field RT against aggressive non-Hodgkin's lymphomas, consistently treated with doxorubicin-based CT, was related to hypothyroidism, but not to CVD (Moser et al 2005).

\section{Gonadal failure}

Despite the continuous improvement of cancer treatment protocols, gonadal failure is a frequent adverse effect in long-term cancer survivors, which may result in hormonal production impairment (hypogonadism), and in the risk of developing MS. It may occur as a consequence of gonadectomy, direct damage of RT to gonads, and/or CT-comprising alkylant drugs (busulfan, cyclophosphamide and iphosphamide) or platinum compounds (carboplatin and cysplatin). So far, estrogens and testosterone are known to influence body composition, lipid metabolism, vascular tone, and blood pressure (Nuver et al 2002; Gleeson and Shalet 2004; Rutter and Rose 2007).

In male gonads, oligo or azoospermia may occur after low-dose RT or alkylating CT, whereas Leydig cells and testosterone production are relatively resistant to damage. On the other hand, in females, RT and cytotoxic treatment may partially or definitively affect both, reproductive function and hormonal production, resulting in premature ovarian failure (POF), with amenorrhea or irregular menses (Nuver et al 2002; Brydøy et al 2007; Rutter and Rose 2007). According to the Childhood Cancer Survivor Study (CCSS), the risk factors to POF in females are: older age at tumor diagnosis, Hodgkin's lymphoma, pelvic RT at or above $10 \mathrm{~Gy}$ or alkylating agents at ages of 13-20 years (Sklar et al 2006). Thus, CT after pubertal onset seems to be more destructive to the ovaries compared to therapy during childhood (Rutter and Rose 2007). Overall, hormone deficiency in both sexes, rather than infertility, is somehow connected to the risk of developing MS features.

\section{Magnesium deficiency}

Systemic anticancer therapies can cause derangement of nonhormonal systems, leading to metabolic disorders, comprising magnesium $\left(\mathrm{Mg}^{+2}\right)$ levels. To date, $\mathrm{Mg}^{+2}$ levels play a role in insulin sensitivity and vascular tone. Generally, hypomagnesemia has been implicated in the development of metabolic disorders, IR and hypertension, increasing the risk of atherosclerosis and CVD (Nuver et al 2002).

Hypomagnesemia is a common effect following cytotoxic agent, particularly cysplatin, but its clinical importance needs to be better evaluated. Possible symptoms of hypomagnesemia are undistinguished from symptoms related to the underlying disease or from the CT-induced symptoms (Nuver et al 2002; Hodgkinson et al 2006). Moreover, after initiation 
of treatment for ALL, rapid recovery in bone formation, which results in the movement of extracellular $\mathrm{Mg}^{+2}$ into the skeleton through bone formation, may be an important contributor to hypomagnesemia (Guo et al 2004).

\section{Other causes}

Vulnerable-child syndrome, lack of adequate physical activity due to damage to the muscles or nerves following CT or RT, altered behavior, energy utilization, and sleep patterns, as well as stress, may also contribute to MS comprising features. Physical inactivity further increases the risk of CVD, osteoporosis, and all-cause mortality. Sleepiness and narcolepsy were reported in craniopharyngioma patients, exacerbating hypothalamic obesity, and were associated with deficiency of orexin and melatonin (Rutter and Rose 2007). Exercise may suppress inflammatory responses and improves insulin sensitivity, rates of protein synthesis and antioxidant activities (Florin et al 2007). Although CT agents may also cause adipose tissue derangement, thus far little is known about this statement.

Mild hyperhomocystinemia is a recently recognized risk factor in the development of CVD, leading to endothelial dysfunction and development of atherosclerosis. It is most commonly secondary to polymorphisms of enzymes involved in homocysteine (Hcy) metabolism, aggravated by the employment of methotrexate, which induces Hcy spikes and endothelial damage (Oeffinger 2008).

\section{Acute lymphocytic leukemia}

Acute lymphocytic leukemia (ALL) is the most common childhood malignancy, and it has been considered an important model to study the metabolic disorders and their relationship to the oncologic disease. Studies from the CCSS have reported an increased risk of all-cause mortality, cardiovascular-related mortality, cerebrovascular accidents, and chronic health conditions in long-term survivors of childhood ALL (Mertens et al 2001).

The association of obesity and cranial RT is wellestablished (Oeffinger 2008). From the CCSS, ALL survivors who have received $>20$ Gy cranial RT (frequently 24 Gy) were at increased risk of overweight/obesity, especially females treated at a young age ( $<5$ years) (Oeffinger et al 2003). Other studies have also confirmed this association of cranial RT and obesity (Sklar et al 2000). Excessive weight gain during ALL treatment is usually related to steroids effects and CNS treatment on appetite regulation, as well as less energy expenditure. Nevertheless, these factors do not fully explain overweight in this group of patients (Dalton et al 2003). Early adiposity rebound (AR) is an additional mechanism that might contribute to obesity in survivors of ALL. The AR is the period of childhood (typically between 5 and 7 years) when BMI and other indexes of adiposity begin to increase after reaching their nadir (Reilly et al 2001). Leptin regulation disorder and leptin resistance have also been hypothesized to play a role in the development of obesity in ALL survivors. Leptin is an important adiposity index during and after ALL therapy as it correlates positively with BMI (Argüelles et al 2000; Adan et al 2001; Siviero-Miachon et al 2007). In addition, leptin receptor polymorphism may also influence obesity in female survivors of childhood ALL, particularly those exposed to cranial RT (Ross et al 2004). On the other hand, most children treated for ALL do not receive cranial RT, or RT dose employed may vary between 12 and 18 Gy (low-dose). Whether CT only or low-dose cranial RT are related to the development of obesity is controversial, but this association has been greatly reported by various previous statements (Argüelles et al 2000; Reilly et al 2001; Dalton et al 2003; Razzouk et al 2007).

Additionally, young adult survivors of childhood ALL are also at risk for MS traits, such as visceral adiposity, dyslipidemia, IR, and hypertension. While CT predisposes to features of MS in ALL survivors, cranial RT increases this predisposition (Talvensaari et al 1996; Oeffinger et al 2001; Link et al 2004; Jarfelt et al 2005; Gurney et al 2006; Janiszewski et al 2007; Trimis et al 2007). All these statements strongly linked the prevalence of MS features to GH deficiency and in turn to cranial RT, even though obesity, and MS traits (as well as GH deficiency) have also been described in patients treated with CT and corticosteroids only (Kourti el al 2005).

\section{Central nervous system tumors}

Obesity and multiple pituitary hormone deficiencies are common complications after treatment of CNS tumors. To date, the major risk factors that predict the development of obesity in CNS tumors survivors are, as follows: hypothalamic location, extent of surgery, hypothalamic irradiation exceeding $51 \mathrm{~Gy}$, and the presence of hypothalamic-pituitary deficiencies, particularly GH deficiency (Lustig et al 2003; Ahmet et al 2006).

Heikens and colleagues (2000) described an altered risk profile for CVD as elevated systolic blood pressure, altered body composition, and a less favorable lipid profile in long-term survivors of childhood CNS tumors (medulloblastoma, astrocitoma, ependymoma, craniopharyngioma and nasopharynx carcinoma), who received cranial RT exceeding 45 Gy. The altered metabolic profile, as well as a larger IMT in the carotid artery bulb, were more pronounced in a subgroup with GH deficiency due to cranial RT, so 
that these changes may be attributed to GH deficiency and predate the development of symptomatic atherosclerosis. Similarly, the existing statements concerning hyperphagia and uncontrolled hypothalamic obesity secondary to craniopharyngioma involve patients treated with either surgery or RT, and correlate findings to GH deficiency due to hypothalamic damage. According to Srinivasan and colleagues (2004), post-craniopharyngioma surgery in children may increase the risk for MS, including IR due to excess weight gain and GH deficiency. However, other possible contributing mechanisms include lack of sensitivity to endogenous leptin (Roth et al 1998), vagally mediated hyperinsulinemia (Lustig et al 2003), autonomic imbalance (Lustig 2003), as well as reduced physical activity (Harz et al 2003).

\section{Sarcomas}

Recently, an increased prevalence of MS traits, comprising hypertension, hypertriglyceridemia, and male visceral abdominal obesity, has been described in pediatric sarcomas survivors (predominantly Ewings), treated with multi-agent CT, and with or without RT (Hoffman et al 2008). Taking into account the NCEP-ATP III criteria (three or more MS traits), there were no differences between the prevalence of MS comparing the study cohort and general population, but young survivors, aged less than 40 years, appear to be more affected (Hoffman et al 2008). This statement concurs with the one stated by the American Heart Association along with the Council for Cardiovascular Disease in the Young, suggesting that post-cancer treatment survivors exhibit epidemiological evidence for manifest CVD early in adult life, and after 30 years of age (Kavey et al 2006). There was no association between MS traits and markers of inflammation and coagulation in pediatric sarcomas survivors. On the other hand, testosterone levels declined as the number of MS features increased, similarly to the condition described to disseminated testicular cancer survivors (Nuver et al 2005; Hoffman et al 2008). No association between GH deficiency and the occurrence of MS traits were observed, although GH deficiency was seen in survivors with or without cranial RT. Physical inactivity due to altered ambulatory function, a consequence of surgical resection and/or RT to thrunk, pelvic and lower extremity may also contribute for the development of MS in pediatric sarcomas survivors (Hoffman et al 2008).

\section{Other types of cancer}

Features of MS have also been described in disseminated testicular cancer, lymphomas, neuroblastomas, and Wilms tumors (Nuver et al 2005; Razzouk et al 2007; Hoffman et al 2008).
The mechanisms involved are similar to those described in other types of cancer. While the association between lymphomas, neuroblastomas, Wilms tumors and MS traits are not often reported, much attention has been given to the relationship between testicular cancer and the features of MS. To date, long-term survivors of disseminated testicular cancer treated with cisplatin-based CT presented with dyslipidemia, hypertension, microalbuminuria, overweight, IR, and increased plasma levels of endothelial and inflammatory marker proteins, which might progress to more severe endothelial dysfunction, and overt atherosclerosis. Testosterone deficiency, rather than other dysfunctions, may play a role in the development of MS in this particular group of patients (Nuver et al 2002; 2005).

\section{Bone marrow transplantation}

Bone marrow transplantation (BMT), including allogeneic and autologous transplantation of stem cells from bone marrow, peripheral blood, and umbilical cord blood, has increased dramatically in recent years. BMT is applied mainly to treat poor-prognosis leukemia and solid tumors, but it is also effective in curing hematological, immunological, genetic, and metabolic nonhematological diseases. As long as the number of BMT increases, the number of long-term survivors of BMT is steadily increasing, and so endocrine effects usually occur as a consequence of pretransplant conditioning regimens. The most common endocrine dysfunctions following BMT are growth disturbances, thyroid dysfunction, gonadal failure, and osteoporosis (Shalitin et al 2006).

Currently, it is becoming clear from a number of studies among adult and pediatric recipients of BMT that they are also at risk of developing abdominal adiposity, IR and other features of MS, such as impaired glucose tolerance, T2DM, dyslipidemia, and hypertension. Early unexplained mortality in adult recipients of BMT has raised concerns regarding accelerated cardiovascular risk in this group of patients (Higgins et al 2004; Chatterjee et al 2005; Neville et al 2006; Shalitin et al 2006; Baker et al 2007; Taskinen et al 2007). The relative risk is influenced by the underlying disease, previous treatments (cranial RT or alkylating CT agents), post-BMT treatments, older age and advanced pubertal stage at BMT, GH deficiency, and genetic predisposition (family history of dyslipidemia and T2DM) (Shalitin et al 2006). TBI, untreated hypogonadism, and abdominal adiposity (a known feature of $\mathrm{GH}$ deficiency), were considered risk factors for the development of hyperinsulinemia, impaired glucose tolerance, and T2DM in pubertal and adult survivors, having TBI the strongest association (Neville et al 2006). Additionally, a waist to height ratio greater than 0.5 in prepubertal subjects 


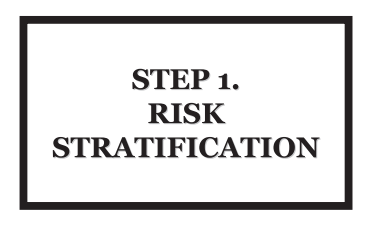

STEP 2. ASSESS ALL

CVD RISK FACTORS

STEP 3. TREATMENT GOALS

STEP 4. LIFESTYLE CHANGE

STEP 5.

DRUG

THERAPY
Tier III: At Risk

Childhood Cancer Survivors

\section{Cardiovascular Risk Factors/Comorbidities}

•Fasting lipid profile

•Smoking history

- Family history of early CVD first degree pedigree ( $M \leq 55 \mathrm{y}$; F $\leq$

65y)

-Blood pressure (3 occasions) interpreted for age/sex/height

$\bullet$ BMI

- Fasting glucose

- Physical activity history

\section{Tier III: At Risk}

$\bullet B M I \leq 95^{\text {th }}$ percentile for sex/age

$\bullet \mathrm{BP} \leq 95^{\text {th }}$ percentile $+5 \mathrm{mmHg}$ for age/sex/height

$\bullet$ LDL-cholesterol $\leq 160 \mathrm{mg} / \mathrm{dL}$

$\bullet$ FG $<100 \mathrm{mg} / \mathrm{dL} ; \mathrm{HbA1c}<7 \%$

Figure I Risk stratification and treatment algorithm of childhood cancer survivors (Adapted from Kavey et al 2006).

Abbreviations: CVD, cardiovascular disease; M, male; F, female; BMI, body mass index; BP, blood pressure; FG, fasting glucose; HbAIC, glycated hemoglobin. 
may represent an early and simple clinical marker for the later development of metabolic disturbance (Neville et al 2006). To date, TBI as a preparative therapy for BMT is the key role in the genesis of IR, as stated by a large multicenter study that included survivors of both pediatric and adult BMT. The risk of developing T2DM was 3 times as likely to occur in BMT recipients as in a control group, and this risk was associated with TBI (Baker et al 2007). Nonetheless, the mechanisms underlying this still remain unclear. TBI has been shown to alter mitochondrial function in muscle, liver, and pancreas, resulting in the development of IR, and T2DM. Other mechanisms related to the immunologic and inflammatory effects of BMT may play a role in the development of such features. To date, the effect of TBI on the function of adipose tissue in secreting adipokines has not been studied yet (Neville et al 2006; Baker et al 2007).

\section{Interventions for cardiovascular risk reduction}

Hormonal supplementation and primary or secondary prevention of endothelial dysfunction are recommended to prevent MS and early atherosclerosis in long-term cancer survivors (Nuver et al 2002).
Primary prevention comprises prevention of hormonal deficiencies and/or direct endothelial damage through more limited surgery, CT dose reduction, avoidance of unnecessary gonadotoxic CT, and the administration of alternative drugs.

Secondary prevention encompasses the following: supplementation of hormonal deficiencies (thyroid, gonadal and/or GH); treatment of therapy-related endothelial dysfunction (IR, dyslipidemia, $\mathrm{Mg}^{+2}$ supplementation); and, finally, screening for the occurrence of MS, and treatment when appropriate (Nuver et al 2002).

Complementary interventional recommendations for cardiovascular risk identification and reduction were developed as a consensus by a writing group convened under the joint direction of the American Heart Association's Expert Panel on Population and Prevention Science and the Council for Cardiovascular Disease in the Young, and an algorithm was developed outlining the risk factor evaluation, management, and therapeutic recommendations (Kavey et al 2006). See Figure 1 and Table 3.

\section{Concluding remarks}

The prevalence and pathogenesis of MS in long-term survivors of cancer, the significance of this syndrome, as well as

Table 3 Treatment recommendations for childhood cancer survivors (Adapted from Kavey et al 2006)

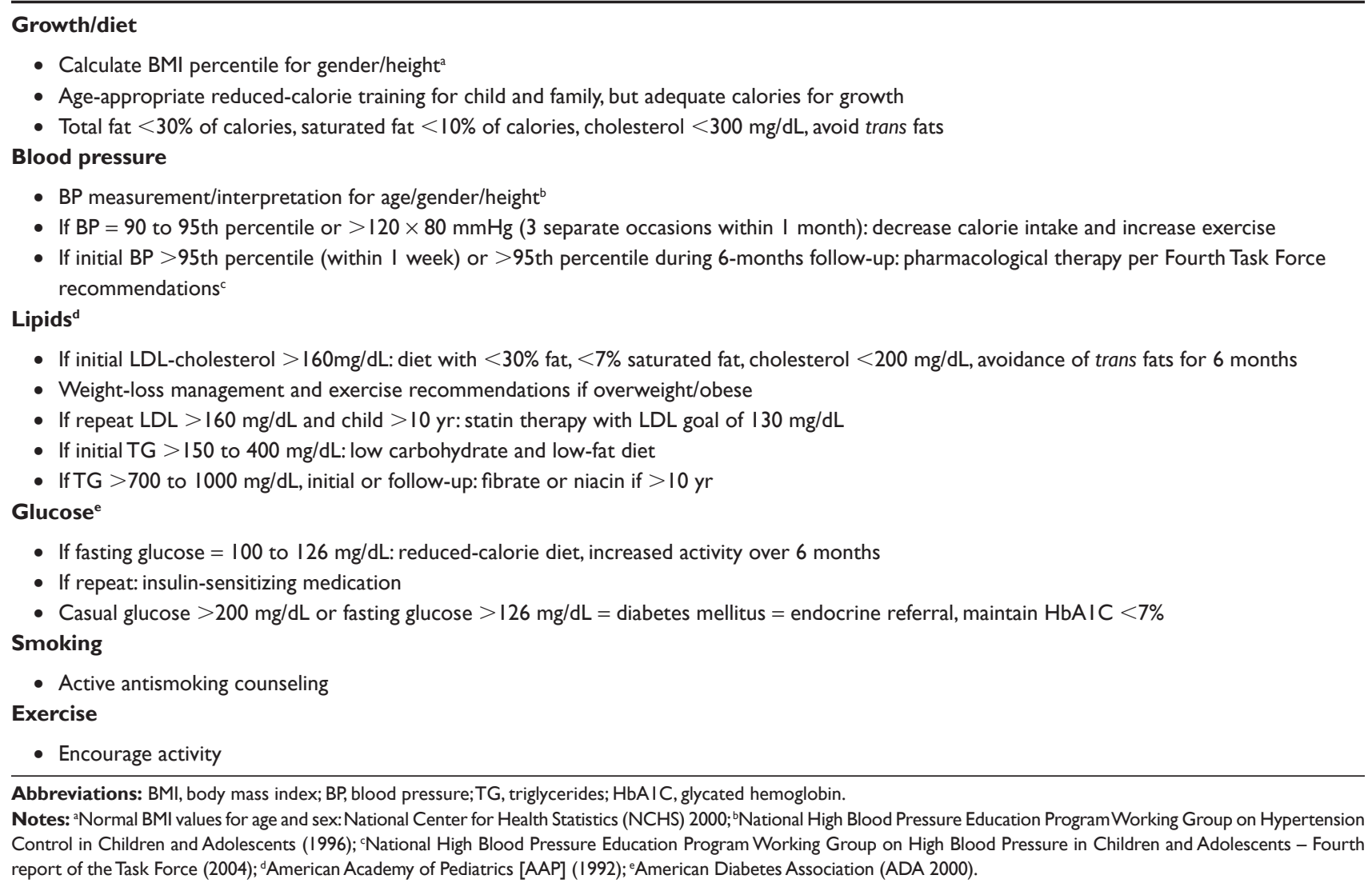


the relationship between MS and the development of CVD after cancer treatment, have to be clarified yet. However, if MS plays an important role in the development of CVD after cancer treatment, this syndrome might be a major target for intervention during follow-up of cancer survivors. The following observations must be considered:

1. Oncologists who treat childhood cancer survivors, and particularly those who provide primary care to adult survivors, should be aware of the potential for long-term hormonal deficiencies and adverse cardiovascular and diabetes risk profiles as a consequence of cancer treatment;

2. Some specific cancer groups predisposing to MS traits, such as ALL, CNS tumors, lymphomas, sarcomas, testicular cancer, and following BMT, as well as RT or alkylating drugs regimens, must call for attention in order to early detect and treat any metabolic alteration or features of MS secondary to therapy;

3. Attempts to prevent the problem of early AR in ALL patients are indicated in the interests of prevention of later obesity. These efforts might take the form of encouraging a more active lifestyle during the first years of therapy;

4. Hypothalamic obesity often results in devastating metabolic and psychosocial complications, requiring provision of dietary and behavioral modifications, encouragement of regular physical activity, psychological counseling, as well as antiobesity drugs;

5. Alternative conditioning therapies for BMT can be considered without compromising survival, reducing the risk of metabolic abnormality. Early detection of abdominal adiposity and/or hormonal deficiency may allow dietary, and lifestyle measures;

6. Therapeutic lifestyle change, with emphasis on weight reduction, constitutes first-line therapy. In patients in whom lifestyle changes fail to reverse metabolic risk factors, consideration should be given to treating specific abnormalities with drugs, according to current treatment guidelines;

7. Overall, further research is still necessary to define the epidemiology, risk factors, and mechanisms behind the development of metabolic disorders in survivors of pediatric cancers, particularly those involving endothelial and adipose tissue dysfunction.

\section{Disclosure}

This work was supported by grants from Fundaco de Amparo a Pesquisa do Estado de Sao Paulo (06/06162-9 to G.G-J.). The authors report no conflicts of interest in this work.

\section{References}

Adan L, Trivin C, Sainte-Rose C, et al. 2001. GH deficiency caused by cranial irradiation during childhood: factors and markers in young adults. J Clin Endocrinol Metab, 86:5245-51.

Ahmet A, Blaser S, Stephens D, et al. 2006. Weight gain in craniopharyngioma -a model for hypothalamic obesity. J Pediatr Endocrinol Metab, 19:121-8

Alberti KGMM, Zimmet PZ. 1998. World Health Organisation (WHO) - Definition, diagnosis and classification of diabetes mellitus and its complications. Part 1: diagnosis and classification of diabetes mellitus provisional report of a WHO consultation. Diabet Med, 15:539-53.

[AAP] American Academy of Pediatrics. 1992. National Cholesterol Education Program: report of the Expert Panel on Blood Cholesterol Levels in Children and Adolescents. Pediatrics, 89(pt 2):525-84.

[ADA] American Diabetes Association. 2000. Type 2 diabetes in children and adolescents. Diabetes Care, 23:381-9.

Argüelles B, Barrios V, Buño M, et al. 2000. Anthropometric parameters and their relationship to serum growth hormone-binding protein and leptin levels in children with acute lymphoblastic leukemia: a prospective study. Eur J Endocrinol, 143:243-50.

Baker KS, Ness KK, Steinberger J, et al. 2007. Diabetes, hypertension, and cardiovascular events in survivors of hematopoietic cell transplantation: a report from the Bone Marrow Transplantation Survivor Study. Blood, 109:1765-72.

Balkau B, Charles MA. 1999. European Group for the Study of Insulin Resistance (EGIR) - Comment on the provisional report from the WHO consultation. European Group for the Study of Insulin Resistance. Diabet Med, 16:442-3.

Barker DJ. 1995. Fetal origins of coronary heart disease. BMJ, 311:171-4. Brydøy M, Fosså SD, Dahl O, et al. 2007. Gonadal dysfunction and fertility problems in cancer survivors. Acta Oncol, 46:480-9.

Bülow B, Link K, Ahren B, et al. 2004. Survivors of childhood acute lymphoblastic leukaemia, with radiation-induced GH deficiency, exhibit hyperleptinaemia and impaired insulin sensitivity, unaffected by 12 months of GH treatment. Clin Endocrinol (Oxf), 61:683-91.

Chatterjee R, Palla K, McGarrigle HH, et al. 2005. Syndrome "X" in adult female recipients of bone marrow transplantation for haematological malignancies. Bone Marrow Transplant, 35:209-10.

Colao A, Di Somma C, Rota F, et al. 2005. Common carotid intima-media thickness in growth hormone $(\mathrm{GH})$-deficient adolescents: a prospective study after GH withdrawal and restarting GH replacement. J Clin Endocrinol Metab, 90:2659-65.

Cook S, Weitzman M, Auinger P, et al. 2003. Prevalence of a metabolic syndrome phenotype in adolescents: findings from the third National Health and Nutrition Examination Survey, 1988-1994. Arch Pediatr Adolesc Med, 157:821-7.

Cruz ML, Weigensberg MJ, Huang TT, et al. 2004. The metabolic syndrome in overweight Hispanic youth and the role of insulin sensitivity. J Clin Endocrinol Metab, 89:108-13.

Dalton VK, Rue M, Silverman LB, et al. 2003. Height and weight in children treated for acute lymphoblastic leukemia: relationship to CNS treatment. J Clin Oncol, 21:2953-60.

DeFerranti SD, Gauvreau K, Ludwig DS, et al. 2004. Prevalence of the metabolic syndrome in American adolescents. Circulation, 110:2494-7.

Einhorn D, Reaven GM, Cobin RH, et al. 2003. The American College of Endocrinology - American College of Endocrinology position statement on the insulin resistance syndrome. Endocr Pract, 9:237-52.

Florin TA, Fryer GE, Miyoshi T, et al. 2007. Physical inactivity in adult survivors of childhood acute lymphoblastic leukemia: a report from the Childhood Cancer Survivor Study. Cancer Epidemiol Biomarkers Prev, 16:1356-63.

Genuth S, Alberti KG, Bennett P, et al. 2003. Follow-up report on the diagnosis of diabetes mellitus. The Expert Committee on the Diagnosis and Classification of Diabetes Mellitus. Diabetes Care, 26:3160-7.

Gleeson HK, Shalet SM. 2004. The impact of cancer therapy on the endocrine system in survivors of childhood brain tumors. Endocr Relat Cancer, 11:589-602. 
Grundy SM, Brewer Jr HB, Cleeman JI, et al. 2004. Definition of metabolic syndrome. Report of the National Heart, Lung, and Blood Institute/ American Heart Association Conference on Scientific Issues Related to Definition. Circulation, 109:433-8.

Guo CY, Halton JM, Barr RD, et al. 2004. Hypomagnesemia associated with chemotherapy in patients treated for acute lymphoblastic leukemia: possible mechanisms. Oncol Rep, 11:185-9.

Gurney JG, Ness KK, Sibley SD, et al. 2006. Metabolic syndrome and growth hormone deficiency in adult survivors of childhood acute lymphoblastic leukemia. Cancer, 107:1303-12.

Harish K, Dharmalingam M, Himanshu M. 2007. Study protocol: insulin and its role in cancer. BMC Endocr Disord, 7:10.

Harz KJ, Müller HL, Waldeck E, et al. 2003. Obesity in patients with craniopharyngioma: assessment of food intake and movement counts indicating physical activity. J Clin Endocrinol Metab, 88:5227-31.

Heikens J, Ubbink MC, Van der Pal HPJ, et al. 2000. Long term survivors of childhood brain cancer have an increased risk for cardiovascular disease. Cancer, 88:2116-21.

Hickman TB, Briefel RR, Carroll MD, et al. 1998. Distributions and trends of serum lipid levels among United States children and adolescents ages 4-19 years: data from the Third National Health and Nutrition Examination Survey. Prev Med, 27:879-90.

Higgins K, Noon C, Cartwright V, et al. 2004. Features of the metabolic syndrome present in bone marrow transplantation in adulthood. Bone Marrow Transplant, 33(suppl 1):S216-S217.

Hodgkinson E, Neville-Webbe HL, Coleman RE. 2006. Magnesium depletion in patients receiving cisplatin-based chemotherapy. Clin Oncol ( $R$ Coll Radiol), 18:710-18.

Hoffman KE, Derdak J, Bernstein D, et al. 2008. Metabolic syndrome traits in long-term survivors of pediatric sarcoma. Pediatr Blood Cancer, 50:341-6.

Hsu IR, Kim SP, Kabir M, et al. 2007. Metabolic syndrome, hyperinsulinemia, and cancer. Am J Clin Nutr, 86:S867-S871.

Hu G, Qiao Q, Tuomilehto J, et al; for the DECODE Study Group. 2004 Prevalence of the metabolic syndrome and its relation to all-cause and cardiovascular mortality in nondiabetic European men and women. Arch Intern Med, 164:1066-76.

[IDF] International Diabetes Federation, 2006. The IDF consensus worldwide definition of the metabolic syndrome [online]. Accessed on January 10, 2008. URL: http://www.idf.org/webdata/docs/IDF_ Meta_def_final.pdf.

Janiszewski PM, Oeffinger KC, Church TS, et al. 2007. Abdominal obesity, liver fat, and muscle composition in survivors of childhood acute lymphoblastic leukemia. J Clin Endocrinol Metab, 92:3816-21.

Jarfelt M, Lannering B, Bosaeus I, et al. 2005. Body composition in young adult survivors of childhood acute lymphoblastic leukaemia. Eur $J$ Endocrinol, 153:81-9.

Jones KL. 2006. The dilemma of the metabolic syndrome in children and adolescents: Disease or distraction? Pediatr Diabetes, 7:311-21.

Kavey RE, Allada V, Daniels SR, et al. 2006. Cardiovascular risk reduction in high-risk pediatric patients: a scientific statement from the American Heart Association Expert Panel on Population and Prevention Science; the Councils on Cardiovascular Disease in the Young, Epidemiology and Prevention, Nutrition, Physical Activity and Metabolism, High Blood Pressure Research, Cardiovascular Nursing, and the Kidney in Heart Disease; and the Interdisciplinary Working Group on Quality of Care and Outcomes Research: endorsed by the American Academy of Pediatrics. Circulation, 114:2710-38.

Kourti M, Tragiannidis A, Makedou A, et al. 2005. Metabolic syndrome in children and adolescents with acute lymphoblastic leukemia after the completion of chemotherapy. J Pediatr Hematol/Oncol, 27:499-501.

Link K, Moëll C, Garwicz S, et al. 2004. Growth hormone deficiency predicts cardiovascular risk in young adults treated for acute lymphoblastic leukemia in childhood. J Clin Endocrinol Metab, 89:5003-12.
Lustig RH. 2003. Autonomic dysfunction of the $\beta$-Cell and the pathogenesis of obesity. Rev Endocr Metab Disord, 4:23-32.

Lustig RH, Post SR, Srivannaboon K, et al. 2003. Risk factors for the development of obesity in children surviving brain tumors. $J$ Clin Endocrinol Metab, 88:611-16.

Mertens AC, Yasui Y, Neglia JP, et al. 2001. Late mortality experience in five-year survivors of childhood and adolescent cancer: the Childhood Cancer Survivor Study. J Clin Oncol, 19:3163-72.

Mohamed-Ali V, Pinkney JH, Coppack SW. 1998. Adipose tissue as an endocrine and paracrine organ. Int J Obes, 22:1145-58.

Moser EC, Noordijk EM, Carde P, et al. 2005. Late non-neoplastic events in patients with aggressive non-Hodgkin's lymphoma in four randomized European Organisation for Research and Treatment of Cancer trials. Clin Lymphoma Myeloma, 6:122-30.

[NCHS] National Center for Health Statistics. 2000 CDC Growth Charts: United States [updated 2007 February 12; cited 2007 November 08] [online] Accessed on January 10, 2008. URL: http://www.cdc.gov/growthcharts

[NCEP-ATP III] National Cholesterol Education Program Adult Treatment Panel III - Expert panel on the detection, evaluation, and treatment of high blood cholesterol in adults. 2001. Executive summary of the Third Report of the National Cholesterol Education Program Expert Panel on Detection, Evaluation, and Treatment of High Blood Cholesterol in Adults (Adult Treatment Panel III). JAMA, 285:2486-97.

National High Blood Pressure Education Program Working Group on Hypertension Control in Children and Adolescents. 1996. Update on the 1987 Task Force Report on High Blood Pressure in Children and Adolescents: a working group report from the National High Blood Pressure Education Program. Pediatrics, 98:649-58.

National High Blood Pressure Education Program Working Group on High Blood Pressure in Children and Adolescents. 2004. Fourth report of the Task Force on the Diagnosis, Evaluation and Treatment of High Blood Pressure in Children. Pediatrics, 114:555-76.

Neville KA, Cohn RJ, Steinbeck KS, et al. 2006. Hyperinsulinemia, impaired glucose tolerance, and diabetes mellitus in survivors of childhood cancer: prevalence and risk factors. J Clin Endocrinol Metab, 91:4401-7.

Nuver J, Smit AJ, Postma A, et al. 2002. The metabolic syndrome in longterm cancer survivors, an important target for secondary preventive measures. Cancer Treat Ver, 28:195-214.

Nuver J, Smit AJ, Wolffenbuttel BH, et al. 2005. The metabolic syndrome and disturbances in hormone levels in long-term survivors of disseminated testicular cancer. J Clin Oncol, 23:3718-25.

Oeffinger KC, Buchanan GR, Eshelman DA, et al. 2001. Cardiovascular risk factors in young adult survivors of childhood acute lymphoblastic leukemia. J Pediatr Hematol/Oncol, 23:424-30.

Oeffinger KC, Mertens AC, Sklar CA, et al. 2003. Obesity in adult survivors of childhood acute lymphoblastic leukemia: A report from the Childhood Cancer Survivor Study. J Clin Oncol, 21:1359-65.

Oeffinger KC. 2008. Are survivors of acute lymphoblastic leukemia (ALL) at increased risk of cardiovascular disease? Pediatr Blood Cancer, $50: 462-7$.

Pollak MN. 2007. Insulin, insulin-like growth factors, insulin resistance, and neoplasia. Am J Clin Nutr, 86:S820-S821.

Razzouk BI, Rose SR, Hongeng S, et al. 2007. Obesity in survivors of childhood acute lymphoblastic leukemia and lymphoma. J Clin Oncol, 25:1183-9.

Reaven GM. 1988. Banting lecture 1988: role of insulin resistance in human disease. Diabetes, 37:1595-607.

Reilly JJ, Kelly A, Ness P, et al. 2001. Premature adiposity rebound in children treated for acute lymphoblastic leukemia. J Clin Endocrinol Metab, 86:2775-8.

Ross JA, Oeffinger KC, Davies SM, et al. 2004. Genetic variation in the leptin receptor gene and obesity in survivors of childhood acute lymphoblastic leukemia: a report from the Childhood Cancer Survivor Study. J Clin Oncol, 22:3558-62.

Roth C, Wilken B, Hanefeld F, et al. 1998. Hyperphagia in children with craniopharyngioma is associated with hyperleptinaemia and a failure in the downregulation of appetite. Eur J Endocrinol, 138:89-91. 
Rutter MM, Rose RS. 2007. Long-term endocrine sequelae of childhood cancer. Curr Opin Pediatr, 19:480-7.

Saini A, Al-Shanti N, Stewart CE. 2006. Waste management - cytokines, growth factors and cachexia. Cytokine Growth Factor Rev, $17: 475-86$.

Sarti C, Gallagher J. 2006. The metabolic syndrome: prevalence, CHD risk, and treatment. $J$ Diabetes Compl, 20:121-32.

Shalitin S, Phillip M, Stein J, et al. 2006. Endocrine dysfunction and parameters of the metabolic syndrome after bone marrow transplantation during childhood and adolescence. Bone Marrow Transplant, 37:1109-17.

Shoelson SE, Lee J, Goldfine AB. 2006. Inflammation and insulin resistance. J Clin Invest, 116:1793-801.

Siviero-Miachon AA, Spinola-Castro AM, Tosta-Hernandez PDC, et al. 2007. Leptin assessment in acute lymphocytic leukemia survivors: role of cranial radiotherapy? J Ped Hematol/Oncol, 29:776-82.

Sklar CA, Mertens AC, Walter A, et al. 2000. Changes in body mass index and prevalence of overweight in survivors of childhood acute lymphoblastic leukemia: role of cranial irradiation. Med Pediatr Oncol, 35:91-5.

Sklar CA, Mertens AC, Mitby P, et al. 2006. Premature menopause in survivors of childhood cancer: a report from the Childhood Cancer Survivor Study. J Natl Cancer Inst, 98:890-6.

Soares DV, Spina LD, de Lima Oliveira Brasil RR, et al. 2005. Carotid artery intima-media thickness and lipid profile in adults with growth hormone deficiency after long-term growth hormone replacement. Metabolism, 54:321-9.

Srinivasan S, Ogle GD, Garnett SP, et al. 2004. Features of the metabolic syndrome after childhood craniopharyngioma. $J$ Clin Endocrinol Metab, 89:81-6.
Szczepaniska-Kostro J, Tolwinska J, Urban M, et al. 2004. Cardiac mass and function, carotid artery intima media thickness, homocysteine and lipoprotein levels in children and adolescents with growth hormone deficiency. J Pediatr Endocrinol Metab, 17:1405-13.

Talvensaari KK, Lanning M, Tapanainen P, et al. 1996. Long-term survivors of childhood cancer have an increased risk of manifesting the metabolic syndrome. J Clin Endocrinol Metab, 81:3051-5.

Taskinen M, Lipsanen-Nyman M, Tiitinen A, et al. 2007. Insufficient growth hormone secretion is associated with metabolic syndrome after allogeneic stem cell transplantation in childhood. J Pediatr Hematol/ Oncol, 29:529-34.

Trimis G, Moschovi M, Papassotiriou I, et al. 2007. Early indicators of dysmetabolic syndrome in young survivors of acute lymphoblastic leukemia in childhood as a target for preventing disease. J Ped Hematol/Oncol, 29:309-14.

Waychenberg BL. 2000. Subcutaneous and visceral adipose tissue: their relation to the metabolic syndrome. Endocr Rev, 21:697-738.

Weiss R, Dziura J, Burgert TS, et al. 2004. Obesity and the metabolic syndrome in children and adolescents. N Engl J Med, 350:2362-74.

Zimmet P, Alberti G, Kaufman F, et al. on behalf of the International Diabetes Federation Task Force on Epidemiology and Prevention of Diabetes. 2007. The metabolic syndrome in children and adolescents. Lancet, 369:2059-61.

Zhou JR, Blackburn GL, Walker WA. 2007. Symposium introduction: metabolic syndrome and the onset of cancer. Am J Clin Nutr, 86: S817-S819. 